\title{
Do Patients with Obstructive Sleep Apnea have an Increased Risk of Desaturation During Induction of Anesthesia for Weight Loss Surgery?
}

\author{
Matthias Eikermann ${ }^{*}, 1,2$, Jaime Garzon-Serrano ${ }^{1}$, Jean Kwo ${ }^{1}$, \\ Martina Grosse-Sundrup ${ }^{1,2}$, Ulrich Schmidt ${ }^{1}$ and Luca Bigatello ${ }^{1}$
}

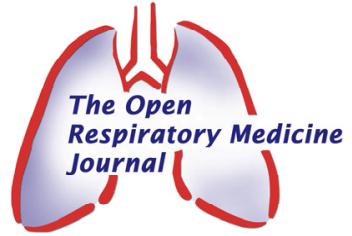

\author{
${ }^{I}$ Department of Anesthesia, Critical Care, and Pain Medicine, Massachusetts General Hospital, and Harvard Medical \\ School, Boston, MA, USA \\ ${ }^{2}$ Universitätsklinikum Essen, Klinik fuer Anästhesie und Intensivmedizin, Essen, Germany
}

\begin{abstract}
Background: Obstructive sleep apnea (OSA) is an independent risk factor to develop perioperative complications during weight loss surgery, but the mechanisms are unclear. It is possible, that patients with OSA have a higher incidence of desaturation during induction of anesthesia.

Methods: We enrolled 100 morbidly obese (body mass index: $53 \pm 10$ ) adult patients undergoing open bariatric surgery in a prospective study. At least $1 \mathrm{~h}$ before induction of anesthesia, peripheral oxygen saturation $\left(\mathrm{SpO}_{2}\right)$ was measured by an oximetry finger probe in the sitting and supine positions, and Mallampati score was taken. Oxygen saturation was recorded also during induction of anesthesia, and nadir values were analyzed, and the STOP-BANG questionnaire was applied.

Results: Thirty-six patients presented with clinical suspicion of OSA. Body weight predicted oxygen saturation in the supine and sitting position, prior to induction of anesthesia. Nadir oxygen saturation during induction of anesthesia was considerably higher in patients with clinical suspicion of OSA, a significant finding that persisted as a trend after correction for age, gender and BMI. The Mallampati score was an independent predictor of OSA, even in morbidly obese patients scheduled for weight loss surgery.

Conclusions: Morbidly obese patients presenting for weight loss surgery have a significant risk to desaturate during induction of anesthesia. A history of OSA does not independently increase the risk of desaturation during induction of anesthesia, if the appropriate precautions are being taken.
\end{abstract}

Keywords: Obstructive sleep apnea, obesity, bariatric surgery, oximetry, anesthesia.

\section{INTRODUCTION}

Currently in the U.S., $32.2 \%$ and $4.8 \%$ of the adult population has a Body Mass Index (BMI) $\geq 30 \mathrm{~kg} / \mathrm{m}^{2}$ and BMI $\geq 40 \mathrm{~kg} / \mathrm{m}^{2}$, respectively $[1,2]$. Obesity represents a special concern for anesthesiologists because it has been associated with difficult airway management [3-5].

Obstructive sleep apnea (OSA) is the most prevalent sleep-associated breathing disorder, affecting $24 \%$ of men and $9 \%$ of women in the general population [6]. Most current evidence suggests that obstructive apnea patients have an anatomical predisposition to pharyngeal collapse on a biomechanical basis [7-9]. Recently it has been shown that OSA is an independent risk factor to develop perioperative complications during weight loss surgery [10], but the contributing mechanisms are unknown.

Anesthetics depress upper airway dilator muscle activity and put the upper airway at risk for collapse [11, 12]. It is

*Address correspondence to this author at the Department of Anesthesia, Critical Care and Pain Medicine, Massachusetts General Hospital, Harvard Medical School, 55 Fruit St, Boston, MA 02114-2696, USA; Tel: 617-6434408; Fax: 617-7265985; E-mail: meikermann@partners.org possible, that patients with OSA have a higher incidence of desaturation during induction of anesthesia. Patients with OSA have a high Mallampati score [13, 14] and a low functional residual capacity $[15,16]$, pathophysiological findings that might be associated with an increased risk of oxygen desaturation during induction of anesthesia [17]. However, OSA patients are typically obese, and it is unclear if their potential susceptibility to desaturation is caused by OSA or rather represents an epiphenomenon of their associated obesity.

We tested the hypotheses that a history of OSA is associated with oxygen desaturation during induction of anesthesia (primary endpoint). Furthermore, we hypothesized that the Mallampati score, even in morbidly obese patients, predicts OSA (secondary endpoint).

\section{METHODS}

After approval of the ethics committee, informed, written consent was obtained from 100 adult subjects who met the criteria for surgical treatment of obesity and underwent to open bariatric surgery. Subjects were older than 18 years and their BMI ranged from 42 to $68 \mathrm{~kg} / \mathrm{m}^{2}$. 


\section{Measurements}

Subjects were evaluated by an anesthesiologist several days before surgery. The following data were prospectively obtained from a detailed medical history and physical examination: Age, gender, American Society of Anesthesiology (ASA) physical status, weight, height, BMI, Mallampati score, history of hypertension (HTN), diabetes mellitus (DM), pulmonary diseases, coronary artery diseases (CAD), chronic renal failure (CRF), psychiatric disorders, the STOPBANG questionnaire $[18,19]$, and a known history of OSA [20]. Diagnosis OSA was made clinically by using the STOP-BANG questionnaire. At least $1 \mathrm{~h}$ before induction of anesthesia, peripheral oxygen saturation $\left(\mathrm{SpO}_{2}\right)$ was measured by an oximetry finger probe $\left(\mathrm{LNCS}^{\circledR}\right.$, Masimo, Irvine, CA) in the sitting and supine positions for 5 minutes each. During induction of general anesthesia we obtained the highest and lowest $\mathrm{SpO}_{2}$ values and the lowest $\mathrm{SpO}_{2}$ value immediately after orotracheal intubation.

Patients were managed by different anesthesiologist with an expertise in bariatric surgery, using the following technique: Preoxigenation prior to induction was performed with the patient in a stacking ramp with reverse Trendelenburg positioning of $25^{\circ}$ (fresh gas flow of $10 \mathrm{~L} / \mathrm{min}$ ) until the end-tidal oxygen saturation was $>90 \%$ or the end-tidal nitrogen concentration was $<5 \%$ gradient between expiratory and inspiratory end-tidal $\mathrm{O}_{2}$ concentration was less than 5-10 $\mathrm{mmHg}$.

Anesthesia was induced with propofol using the adjusted dose formula (adjusted dose $=$ ideal body weight $($ IBW) dose $\mathrm{x}[1+.007$ (total body weight - IBW) $]$ ), fentanyl, and cisatracurium and two-hand mask ventilation technique was performed when needed. Anesthesia was maintained with isoflurane or desflurane, and remifentanil, and neuromuscular blockade was maintained with cisatracurium, and reversed with neostigmine. Intraoperatively, subjects received IV morphine sulfate or IV hydromorphone.

\section{Statistics}

Based on previous findings, suggesting that patients with OSA are at greater risk of having hypoxemia in the perioperative setting [6], we tested the primary hypothesis that nadir $\mathrm{SpO}_{2}$ during induction of anesthesia is lower in obese patients with clinical suspicion of OSA compared with obese patients without OSA. Based on the observation of Nuckton et al. and Hiremath et al. [13, 14], we tested the secondary hypothesis that a high Mallampati score is associated with clinical suspicion of OSA.

Multiple linear regression analysis was used to determine the effect of age [21], weight, BMI, gender, ASA class, as well as a history of: sleep apnea, respiratory, cardiovascular and/or psychiatric disease on oxygen saturation. We also tested by multiple linear regression analysis if the Mallampati score independently predicts patients with clinical suspicion of OSA.

The Mann-Whitney-U test was used to test for statistical significance between patients with and without clinical suspicion of OSA.

As for the sample size estimation, we expected a differences in Mallampati score between obese patients with and without OSA of 0.5 with a standard deviation of 0.3 , and a difference in nadir oxygen saturation between obese patients with clinical suspicion of OSA and controls of $1 \%$ (standard deviation: 1\%). Based on these assumptions, we calculated that a sample size of 90 patients provides an $80 \%$ power to detect a significant difference in nadir $\mathrm{SpO}_{2}$ during induction of anesthesia, if present.

Data (means \pm SD) were analyzed using SPSS software (version 11, SPSS, Chicago, IL).

\section{RESULTS}

100 patients were included in this study. Five patients were excluded (missing data related to assessment of primary and/or secondary endpoint), such that data from 95 patients are presented.

Patients with clinical suspicion of OSA $(n=36)$ presented with higher $(p<0.05)$ age, weight, BMI, and ASA class probably related to a higher incidence of diabetes and coronary artery disease. Male gender was also associated with clinical suspicion of OSA (Table 1).

Table 1. Baseline Characteristics

\begin{tabular}{|c|c|c|}
\hline & OSA $(n=36)$ & Non-OSA $(n=59)$ \\
\hline Gender & $\begin{array}{l}50 \% \text { female, } \\
50 \% \text { male* }\end{array}$ & $\begin{array}{l}85 \% \text { female, } \\
15 \% \text { male }\end{array}$ \\
\hline Age [years] & $45.8 \pm 11 *$ & $41 \pm 10$ \\
\hline Weight [kg] & $166 \pm 35^{*}$ & $144 \pm 33$ \\
\hline Height [cm] & $171 \pm 11$ & $167 \pm 10$ \\
\hline BMI & $57 \pm 11^{*}$ & $51.4 \pm 9$ \\
\hline ASA & $3[1-4]^{*}$ & $2[1-4]$ \\
\hline $\begin{array}{l}\text { History of } \\
\text { Hypertension }\end{array}$ & $30 \%(\mathrm{n}=11), \mathrm{ns}$ & $30 \%(\mathrm{n}=18)$ \\
\hline $\begin{array}{l}\text { History of Diabetes } \\
\text { Mellitus }\end{array}$ & $\begin{array}{c}33 \%(\mathrm{n}=12) \mathrm{p}=0.08 \\
v s \text { controls }\end{array}$ & $18 \%(\mathrm{n}=11)$ \\
\hline $\begin{array}{l}\text { History of Coronary } \\
\text { Artery Disease }\end{array}$ & $\begin{array}{c}16 \%(\mathrm{n}=6), \mathrm{p}=0.1 \\
v s \text { controls }\end{array}$ & $7 \%(n=4)$ \\
\hline $\begin{array}{l}\text { History of } \\
\text { Respiratory Disease }\end{array}$ & $33 \%(\mathrm{n}=12), \mathrm{ns}$ & $27 \%(\mathrm{n}=16)$ \\
\hline $\begin{array}{l}\text { History of } \\
\text { Psychiatric Disease }\end{array}$ & $10 \%(\mathrm{n}=4), \mathrm{ns}$ & $11 \%(n=6)$ \\
\hline History of CRF & $2.8 \%(\mathrm{n}=1), \mathrm{ns}$ & 0 \\
\hline
\end{tabular}

Patients with clinical suspicion of OSA presented at hospital admission with an observed apnea (40\%), snoring (40\%) and excessive daytime sleepiness (35\%). A previous polysomnogram (PSG) confirming the diagnosis of OSA was available from $27 \%$ of the patients. The STOP-BANG scoring model revealed that all but one patient had 3 or more positive items suggesting high risk of OSA.

In patients with OSA, the mean apnea/hypopnea index was $34 \pm 34$ (means \pm SD). $65 \%$ of the patients had a moderate OSA and $35 \%$ severe.

Patients with clinical suspicion of OSA had lower preoperative $\mathrm{SpO}_{2}$ in the supine (96.2 \pm 2.6$)$ and sitting 
position (96.9 \pm 2$)$ vs patients with no history of clinical suspicion of OSA $(97.2 \pm 2.1$ and $97.8 \pm 1.8, p<0.05$ and $\mathrm{p}<0.02$, respectively), but these differences disappeared when adjusted for BMI, age, and gender (Fig. 1).

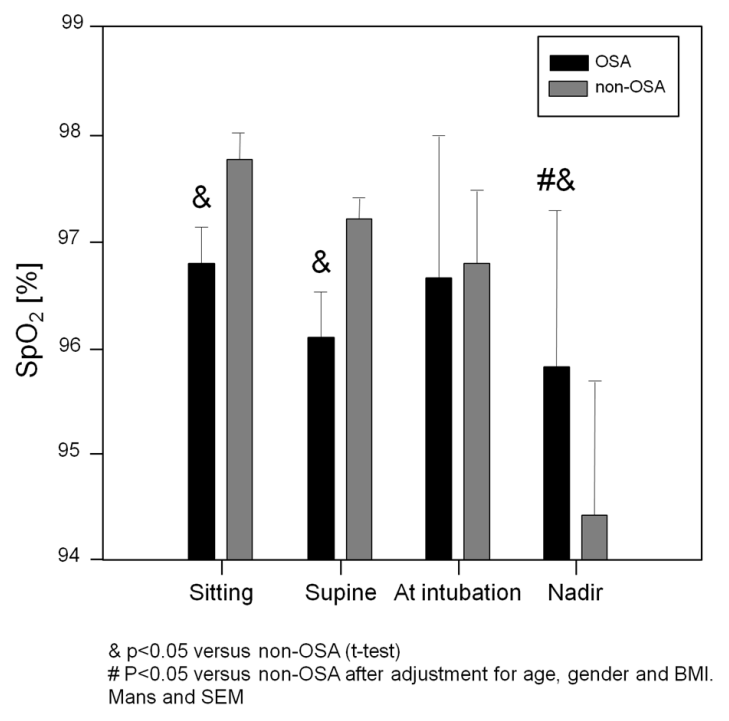

Fig. (1). Means and standard deviations of peripheral oxygen saturation $\left(\mathrm{SpO}_{2)}\right.$ before and during induction of anesthesia. In the sitting and supine positions, patients with history of OSA was significantly lower $\mathrm{SpO}_{2}$. Nadir $\mathrm{SpO}_{2}$ was remarkably lower in patients without history of OSA.

Higher BMI predicted low preoperative $\mathrm{SpO}_{2}$ values in both supine $(r=-0.23, p=0.02)$ and sitting positions $(r=-0.21$, $\mathrm{p}=0.03$ ).

Paradoxically, nadir oxygen saturation was higher in patients with clinical suspicion of OSA compared with patients with no history of clinical suspicion of OSA, an observation that persisted as a trend $(\mathrm{p}=0.1)$ even after adjustment for BMI, age, and gender (Fig. 2).

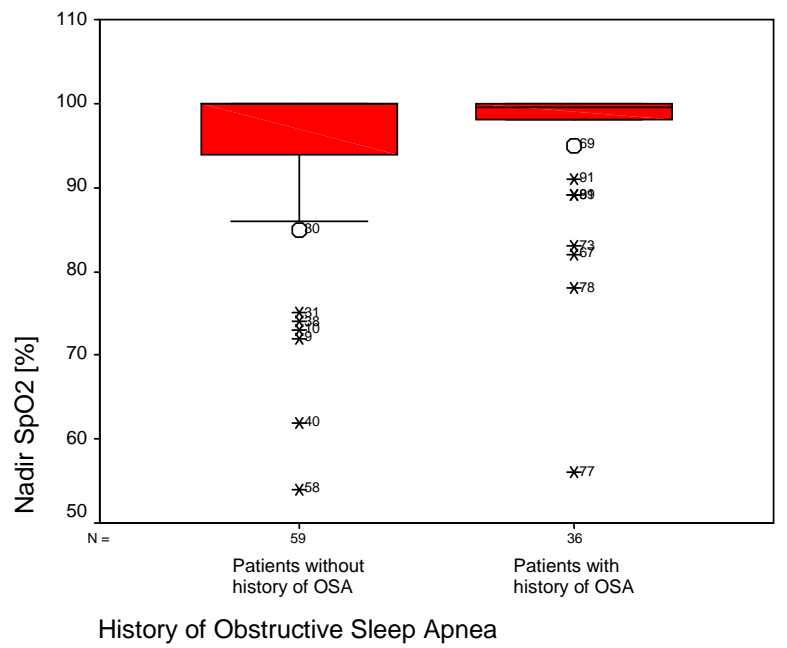

Fig. (2). Nadir peripheral oxygen saturation ( $\mathrm{SpO} 2)$ during induction of anesthesia. Box plots of quartiles (boxes), median (line within box), $10^{\text {th }}$, and $90^{\text {th }}$ percentiles (error bars, outliers' ID is given as open circles). Median of nadir oxygen saturation is significantly higher in patients with a history of OSA.
Multiple regression analysis revealed that the Mallampati score (OSA: $2.1 \pm 0.6$ [means $\pm \mathrm{SD}$ ] vs $1.7 \pm 0.7$ in patients with no history of clinical suspicion of OSA) was an independent predictor of OSA.

\section{DISCUSSION}

Nadir oxygen saturation during induction of anesthesia was considerably higher in patients with clinical suspicion of OSA, a significant finding that persisted as a trend after correction for age, gender and BMI. The Mallampati score was predictive for a clinical suspicion of OSA defined by the STOP BANG questionnaire, in morbidly obese patients scheduled for weight loss surgery.

Difficult intubation is common in obstructive sleep apnea patients and, vice versa, obstructive sleep apnea is common in patients with difficult intubation [22]. Some studies [14, $23,24]$, reported in patients with OSA compared with controls a high prevalence (up to 8 fold higher [25]) of difficult tracheal intubation, a finding that is in accordance with the association between Mallampati score, a predictor of both difficult intubation [26], and the incidence and severity of OSA [13, 27-29]. Accordingly, it has been suggested that an upper airway anatomical imbalance is involved in the pathogenesis of OSA [30].

Our patients with clinical suspicion of OSA had a significantly higher Mallampati score, confirming the clinical utility of the Mallampati score as a predictor of OSA, even in morbidly obese patients. This is an important finding, because obesity itself is associated with an increased Mallampati score [31, 32], Accordingly, the clinician should consider that a high Mallampati score, even in obese patients, might indicate an increased risk of OSA.

The association between Mallampati score and a clinical suspicion of OSA did not translate to an increased risk of intraoperative oxygen desaturation in these patients. In fact, obese patients with clinical suspicion of OSA had even a higher $\mathrm{SpO}_{2}$ nadir during anesthesia induction, compared with obese patients without OSA. We don't know the contributing mechanisms of this unexpected finding. We conducted an observational study and we speculate that the anesthesiologists responsible for taking care of these patients being aware of a patient's history of obstructive apnea, used more efficient strategies to prevent oxygen desaturation during induction, even though they were following a standardized anesthetic plan. Obese patients with OSA have a markedly decreased in FRC [17] putting a patient at risk to deoxygenate during a short apnea. Adequate patient positioning during preoxygenation improves apnea tolerance [33]. Accordingly, it has been recommended that the sniffing position in the Fowler's (semi-sitting) position is optimal for anesthesia induction in morbidly obese patients with severe OSA [34]. Independent of positioning, it is also possible that anesthesiologist taking care of patients with a history of OSA applied preoxygenation for a longer period of time prior to induction.

Oxygen saturation in the supine and sitting position, prior to induction of anesthesia, was lower in obese patients clinical suspicion of OSA compared to obese patients without, but the results of our multiple regression analysis suggest that the effects are related to obesity rather than to OSA itself. It is not surprising that OSA is not an 
independent risk factor for oxygen desaturation during wakefulness. Most current evidence suggests that OSA patients have an anatomical predisposition to pharyngeal collapse on a biomechanical basis $[7,8]$. Through protective reflex mechanisms that drive activation of dilator muscles, pharyngeal patency is well maintained during wakefulness. However, these protective reflexes are diminished during sleep, leading to collapse of the pharyngeal airway in anatomically predisposed individuals [35].

In our study, independent of OSA, the BMI was associated with low preoperative values of oxygen saturation. Obesity can alter respiratory physiology by two main mechanisms: effect of excessive tissue on upper airway and pulmonary function [16], and effects of obesity on neurologic control of upper airway and respiratory pump muscles [17]. A combination of FRC decrease, increased oxygen consumption, and hypoventilation during sleep may explain the association between BMI and low preoperative oxygen saturation during wakefulness.

\section{LIMITATIONS}

Our study has several limitations. Diagnosis OSA was based on clinical data, but overnight in-laboratory polysomnography is the traditional golden standard for diagnosing OSA [37]. This conventional approach has been considered costly and technically complex and may present scheduling difficulties when there is high demand, and other approaches considered for their potential to reduce costs and increase accessibility have also been evaluated [17, 36, 37]. Although to date the diagnosis is no longer that time and resource-consuming [37], in some situations it may delay surgery when the diagnosis is considered essential for anesthetic management.

We have used the STOP questionnaire, a concise and easy-to-use screening tool for OSA. It has been developed and validated in surgical patients at preoperative clinics. Combined with body mass index, age, neck size, and gender, as accomplished in our study, the score as an acceptable sensitivity, especially for patients with moderate to severe OSA.

We did not take arterial blood gas analyses, representing a more sensitive method for measurement of deoxygenation than peripheral oxygen saturation. The observation higher nadir values of peripheral oxygen saturation observed in patients with a history of OSA prior to intubation strongly suggest that our patients with sleep apnea have not been more prone to deoxygenation during induction of anesthesia for weight loss surgery.

Finally, it would be interesting to report values of the arterio-alveolar carbon dioxide gradient in our patients, as to characterize dead-space ventilation and obesity hypoventilation syndrome.

In summary, the clinician should consider that morbidly obese patients presenting for weight loss surgery have a significant risk to desaturate during induction of anesthesia. A history of OSA does not independently increase the risk of desaturation during induction of anesthesia, if the appropriate precautions are being taken.

\section{ACKNOWLEDGEMENT}

This work was supported by funds from the Massachusetts General Hospital Department of Anesthesia Critical Care and Pain Medicine, Boston, Massachusetts.

\section{REFERENCES}

[1] Ogden CL, Carroll MD, Curtin LR, McDowell MA, Tabak CJ, Flegal KM. Prevalence of overweight and obesity in the United States 1999-2004. JAMA 2006; 295: 1549-55.

[2] Schwartz AR, Patil SP, Laffan AM, Polotsky V, Schneider H, Smith PL. Obesity and obstructive sleep apnea: pathogenic mechanisms and therapeutic approaches. Proc Am Thorac Soc 2008; 5: 185-92.

[3] Cook TM. Difficult airway in an obese patient managed with the ProSeal laryngeal mask airway. Eur J Anaesthesiol 2005; 22: 2413.

[4] Dhonneur G, Abdi W, Ndoko SK, et al. Video-assisted versus conventional tracheal intubation in morbidly obese patients. Obes Surg 2009; 19: 1096-101.

[5] Martin TJ, Hartnett JM, Jacobson DJ, Gross JB. Care of a parturient with preeclampsia, morbid obesity, and Crouzon's syndrome. Int J Obstet Anesth 2008; 17: 177-81.

[6] Chung F, Elsaid H. Screening for obstructive sleep apnea before surgery: why is it important? Curr Opin Anaesthesiol 2009; 22 405-11.

[7] Remmers JE, deGroot WJ, Sauerland EK, Anch AM. Pathogenesis of upper airway occlusion during sleep. J Appl Physiol 1978; 44: 931-8.

[8] Schwab RJ, Pasirstein M, Pierson R, et al. Identification of upper airway anatomic risk factors for obstructive sleep apnea with volumetric magnetic resonance imaging. Am J Respir Crit Care Med 2003; 168: 522-30.

[9] Barcelo X, Mirapeix RM, Domingo C. Surgical treatment of the sleep apnea syndrome in the twenty-first century. Curr Resp Med Rev 2008; 4: 187-207.

[10] Flum DR, Belle SH, King WC, et al. Perioperative safety in the longitudinal assessment of bariatric surgery. N Engl J Med 2009; 361: 445-54

[11] Eikermann M, Fassbender P, Zaremba S, et al. Pentobarbital dosedependently increases respiratory genioglossus muscle activity while impairing diaphragmatic function in anesthetized rats. Anesthesiology 2009; 110: 1327-34.

[12] Eikermann M, Eckert DJ, Chamberlin NL, et al. Effects of pentobarbital on upper airway patency during sleep. Eur Respir J 2009 [Epub ahead of print].

[13] Nuckton TJ, Glidden DV, Browner WS, Claman DM. Physical examination: Mallampati score as an independent predictor of obstructive sleep apnea. Sleep 2006; 29: 903-8.

[14] Hiremath AS, Hillman DR, James AL, Noffsinger WJ, Platt PR, Singer SL. Relationship between difficult tracheal intubation and obstructive sleep apnoea. Br J Anaesth 1998; 80: 606-11.

[15] Bedell GN, Wilson WR, Seebohm PM. Pulmonary function in obese persons. J Clin Invest 1958; 37: 1049-60.

[16] Eikermann M. Respiratory concerns in the obese patient. In: Ortiz V, Wiener-Kronish J, Eds. Perioperative anesthetic care of the obese patient. New York: Informa Healthcare 2010; pp. 12-20.

[17] Isono S. Obstructive sleep apnea of obese adults: pathophysiology and perioperative airway management. Anesthesiology 2009; 110 908-21.

[18] Chung F, Yegneswaran B, Liao P, et al. STOP questionnaire: a tool to screen patients for obstructive sleep apnea. Anesthesiology 2008; 108: 812-21

[19] Overdyk FJ, Ahmed QA, Rust PF. STOP questionnaire warrants CAUTION sign. Anesthesiology 2009; 110: 193.

[20] Gali B, Whalen FX, Schroeder DR, Gay PC, Plevak DJ. Identification of patients at risk for postoperative respiratory complications using a preoperative obstructive sleep apnea screening tool and postanesthesia care assessment. Anesthesiology 2009; 110: 869-77.

[21] Eikermann M, Jordan AS, Chamberlin NL, et al. The influence of aging on pharyngeal collapsibility during sleep. Chest 2007; 131: $1702-9$. 
[22] Isono S. Difficult tracheal intubation and a low hyoid. Anesthesiology 2009; 110: 431.

[23] Siyam MA, Benhamou D. Difficult endotracheal intubation in patients with sleep apnea syndrome. Anesth Analg 2002; 95: 1098102.

[24] Chung F, Yegneswaran B, Herrera F, Shenderey A, Shapiro CM. Patients with difficult intubation may need referral to sleep clinics. Anesth Analg 2008; 107: 915-20.

[25] Chung SA, Yuan H, Chung F. A systemic review of obstructive sleep apnea and its implications for anesthesiologists. Anesth Analg 2008; 107: 1543-63.

[26] Shiga T, Wajima Z, Inoue T, Sakamoto A. Predicting difficult intubation in apparently normal patients: a meta-analysis of bedside screening test performance. Anesthesiology 2005; 103: 429-37.

[27] Hillman DR, Loadsman JA, Platt PR, Eastwood PR. Obstructive sleep apnoea and anaesthesia. Sleep Med Rev 2004; 8: 459-71.

[28] Friedman M, Tanyeri H, La Rosa M, et al. Clinical predictors of obstructive sleep apnea. Laryngoscope 1999; 109: 1901-7.

[29] Zonato AI, Bittencourt LR, Martinho FL, Junior JF, Gregorio LC, Tufik S. Association of systematic head and neck physical examination with severity of obstructive sleep apnea-hypopnea syndrome. Laryngoscope 2003; 113: 973-80.

[30] Tsuiki S, Isono S, Ishikawa T, Yamashiro Y, Tatsumi K, Nishino T. Anatomical balance of the upper airway and obstructive sleep apnea. Anesthesiology 2008; 108: 1009-15.
[31] Voyagis GS, Kyriakis KP, Dimitriou V, Vrettou I. Value of oropharyngeal Mallampati classification in predicting difficult laryngoscopy among obese patients. Eur J Anaesthesiol 1998; 15: 330-4.

[32] Juvin P, Lavaut E, Dupont H, et al. Difficult tracheal intubation is more common in obese than in lean patients. Anesth Analg 2003; 97: 595-600.

[33] Altermatt FR, Munoz HR, Delfino AE, Cortinez LI. Preoxygenation in the obese patient: effects of position on tolerance to apnoea. Br J Anaesth 2005; 95: 706-9.

[34] Isono S. Optimal combination of head, mandible and body positions for pharyngeal airway maintenance during perioperative period: Lesson from pharyngeal closing pressures. Semin Anesth Periop Med Pain 2007; 26: 83-93.

[35] Mezzanotte WS, Tangel DJ, White DP. Waking genioglossal electromyogram in sleep apnea patients versus normal controls (a neuromuscular compensatory mechanism). J Clin Invest 1992; 89: 1571-9.

[36] Kushida CA, Littner MR, Morgenthaler $\mathrm{T}$, et al. Practice parameters for the indications for polysomnography and related procedures: an update for 2005. Sleep 2005; 28: 499-521.

[37] Domingo C, Vigil L. Effectiveness of unattended ambulatory sleep studies for the diagnosis and treatment of obstructive sleep apnea syndrome. J Eval Clin Prac 2010 [Epub ahead of print].

Received: April 13, 2010

Revised: April 23, 2010

Accepted: May 5, 2010

(C) Eikermann et al.; Licensee Bentham Open.

This is an open access article licensed under the terms of the Creative Commons Attribution Non-Commercial License (http://creativecommons.org/licenses/ by-nc/3.0/) which permits unrestricted, non-commercial use, distribution and reproduction in any medium, provided the work is properly cited. 